\title{
Selecting the Best Hitter in a Professional Baseball League Using the Technique for Order of Preference by Similarity to Ideal Solution
}

\author{
Selecting Best Hitter in Pro-Baseball League
}

\author{
Chih-Cheng Chen ${ }^{1, *}$, Yen-Whea Kuo ${ }^{2}$, Chih-Jen Chuang ${ }^{1}$, Chun-Hsiao Chu ${ }^{3}$, Tian-Shaing Kuo ${ }^{4}$ and Kuang-Tsan \\ Hung $^{5}$ \\ ${ }^{1}$ Department of Sport Management, Aletheia University, New Taipei City, Taiwan \\ ${ }^{2}$ Center for Physical Education, Aletheia University, New Taipei City, Taiwan \\ ${ }^{3}$ Department \& Graduate Institute of Tourism, Aletheia University, New Taipei City, Taiwan \\ ${ }^{4}$ Bachelors Degree Program of Dynamic Recreation and Health Management, Tainan \\ ${ }^{5}$ Department of Physical Education, De Lin Institute of Technology, New Taipei City, Taiwan \\ ${ }^{*}$ Corresponding author
}

\begin{abstract}
Selecting the best hitter in a professional baseball league is considered a multi-attribute decision-making problem. We developed an evaluation model based on literature review and the Technique for Order of Preference by Similarity to Ideal Solution (TOPSIS) to select the best hitter in the Chinese Professional Baseball League. We determined attribute weights and used the TOPSIS to calculate the individual performance ranking. We conducted an empirical analysis to demonstrate the applicability of the proposed model for addressing the problem associated with hitter performance. The results demonstrate the effectiveness and feasibility of the proposed model.
\end{abstract}

Keywords-hitter; Technique for Order of Preference by Similarity to Ideal Solution (TOPSIS); Chinese Professional Baseball League; plate appearances (PAs); on-base percentage (OBP); slugging percentage (SLG)

\section{INTRODUCTION}

A baseball game involves two teams: offense and defense. The offense attempts to score by using a bat to hit a ball thrown by the pitcher, thus putting the ball in play, and the hitter scores a run by moving counter-clockwise around a series of four bases: first, second, third, and, finally, home plate. The defense attempts to prevent the scoring of runs by getting the hitter out. To win a baseball game, a team must score more runs than the opponent. Pitchers, whose aim is to prevent the offense from hitting and subsequently scoring, are particularly crucial in a baseball game[1-2]. Therefore, pitchers and hitters are equally valuable to a baseball team. Each year, as the playing season progresses, baseball fans and sportswriters worldwide take great interest in discussing which pitcher or hitter is the best in a professional baseball league. In addition, selecting a pitcher or hitter is a decision-making problem for a complex system that includes many quantitative attributes [1]. Most baseballrelated decision-making studies have focused on selecting pitchers for particular themes [1, 3-4], and rarely on selecting hitters. Thus, in this study, we focused on selecting hitters. As mentioned, in a professional baseball game, scoring runs is the main objective of the batting team, and this is accomplished through a combination of skills, particularly the skills of hitting the ball and avoiding getting out [5-6]. However, in the world of sports, this message often appears lost. The best baseball players are often valued if they demonstrate the five attributes of hitting for average, hitting for power, running, throwing, and fielding. In other words, a nonspecialist hitter is preferred in baseball [7]. Thus, selecting the best baseball hitter is a type of multi-attribute decision-making (MADM) problem. In this study, we applied methods used in previous studies on professional baseball [5-6] to determine the weight of each attribute. Specifically, we used the Technique for Order of Preference by Similarity to Ideal Solution (TOPSIS), which is a multi-criteria decision analysis method for calculating the distance of each alternative from positive and negative ideal solutions, instead of ranking the alternatives [3]. The remainder of this article is organized as follows. Section 2 presents the methodology for evaluation. Section 3 focuses on empirical analysis for determining the best hitter in the Chinese Professional Baseball League (CPBL). Finally, Section 4 draws conclusions and offers recommendations for future study.

\section{MATERIAL AND METHODS}

\section{A. TOPSIS Method}

The TOPSIS, which was initially proposed by Hwang and Yoon, is based on the concept of distance measures [3, 8]. An ideal solution (a positive ideal solution) maximizes the benefit criteria or attributes and minimizes the cost criteria or attributes. Conversely, an antiideal ideal solution (a negative solution) maximizes the cost criteria or attributes and minimizes the benefit criteria or attributes $[3,8]$.

The TOPSIS is explained as follows [8]:

Step1. Obtain performance data for $m$ alternatives over $n$ attributes. Raw measurements are generally standardized by converting raw measures $X_{i j}$ into standardized measures $S_{i j}$. 
Step2. Develop a set of importance weights $W_{k}$ for each criterion. These weights are typically ad hoc reflective of relative importance. Scale is not a concern if the weights are standardized in Step 1.

Step3. Identify an ideal alternative (extreme performance in each criterion) $S^{+}$.

Step4. Identify a nadir alternative (reverse extreme performance in each criterion) $S^{-}$.

Step5. Develop a distance measure over each criterion to include both ideal $\left(D^{+}\right)$and nadir $\left(D^{-}\right)$.

Step6. For each alternative, determine a ratio $\mathrm{R}$ equal to the distance to the nadir divided by the sum of the distance to the nadir and the distance to the ideal as follows:

$$
\mathrm{R}=D^{-} /\left(D^{+}+D^{-}\right) \text {. }
$$

Step7. Rank order alternatives by maximizing $\mathrm{R}$ obtained in Step 6.

Thus, the TOPSIS minimizes the distance to the ideal alternative while maximizing the distance to the nadir. Several procedures can be used for Step 2 (developing weights) and Step 5 (distance measures). Additionally, different conventions can be used for defining the best performance (Step 3) and the worst performance (Step 4).

\section{B. Data}

We obtained data from the official CPBL website (http://www.cpbl.com.tw), which collected and posted records of every CPBL game in 2013. We selected alternative players for the teams in 2013 from the website. Every alternative player chosen had at least 372 plate appearances (PAs) in the 2013 season. The commonly cited statistics for hitters found in the empirical analysis were on-base percentage (OBP) and slugging percentage (SLG) [5-6], both of which significantly contribute to the team winning percentage [5], We included these attributes and performed calculation by using the TOPSIS, in which parameters used as attributes are familiar to many baseball fans.

\section{RESUlts AND DiscUSSION}

\section{A. Information on the Performance of Alternative Hitters}

To safeguard CPBL player interests, we did not use the actual player names in the paper. A brief description and the code names of $22 \mathrm{CPBL}$ hitters is provided in Table 1 . In the 2013 season, all alternative hitters had an OBP > .288 (Table 1) Player A3 had the best OBP (.419). There was a tie between Players A4 and A5 for second place. The SLG of all of the hitters was $>$.319. Player A18 was the best performer; Players A4 and A5 ranked second and third, respectively. However, based on these results, we could not clearly determine which player was the best hitter in the 2013 season.
TABLE I. ALTERNATIVE HITTERS' PERFORMANCE INFORMATION

\begin{tabular}{|c|c|c|c|c|}
\hline Player & $\boldsymbol{G}$ & $\boldsymbol{P A s}$ & $\boldsymbol{O B P}$ & $\boldsymbol{S L G}$ \\
\hline A1 & 119 & $505(1)$ & $0.329(15)$ & $0.417(9)$ \\
\hline A2 & 117 & $486(2)$ & $0.298(21)$ & $0.319(22)$ \\
\hline A3 & 116 & $477(3)$ & $0.419(1)$ & $0.454(6)$ \\
\hline A4 & 113 & $467(4)$ & $0.415(2)$ & $0.549(2)$ \\
\hline A5 & 112 & $460(5)$ & $0.415(2)$ & $0.498(3)$ \\
\hline A6 & 113 & $449(6)$ & $0.308(18)$ & $0.330(20)$ \\
A7 & 112 & $447(7)$ & $0.331(13)$ & $0.383(10)$ \\
A8 & 105 & $445(8)$ & $0.373(6)$ & $0.451(7)$ \\
A9 & 103 & $438(9)$ & $0.336(12)$ & $0.369(12)$ \\
A10 & 113 & $436(10)$ & $0.306(19)$ & $0.342(16)$ \\
A11 & 100 & $436(10)$ & $0.322(16)$ & $0.364(13)$ \\
A12 & 98 & $434(12)$ & $0.351(10)$ & $0.361(15)$ \\
A13 & 101 & $433(13)$ & $0.376(5)$ & $0.439(8)$ \\
A14 & 99 & $414(14)$ & $0.368(7)$ & $0.466(5)$ \\
A15 & 114 & $412(15)$ & $0.288(22)$ & $0.374(11)$ \\
A16 & 114 & $407(16)$ & $0.310(17)$ & $0.331(19)$ \\
A17 & 101 & $401(17)$ & $0.331(14)$ & $0.323(21)$ \\
A18 & 102 & $398(18)$ & $0.411(4)$ & $0.566(1)$ \\
A19 & 106 & $398(18)$ & $0.357(8)$ & $0.478(4)$ \\
A20 & 99 & $388(20)$ & $0.352(9)$ & $0.362(14)$ \\
A21 & 111 & $384(21)$ & $0.303(20)$ & $0.338(17)$ \\
A22 & 101 & $382(22)$ & $0.347(11)$ & $0.338(17)$ \\
\hline
\end{tabular}

\section{B. Using the TOPSIS to determine the best hitter}

Based on the data in Table I, we performed the TOPSIS as follows. We used Step 1 to calculate the normalized decision matrix depending on whether the objective of the selection attribute is minimization or maximization. Table II shows the normalized decision matrices of each hitter. The objective of all attributes was maximization.

TABLE II. NORMALIZED DECISION MATRIXES

\begin{tabular}{|c|c|c|}
\hline Player & $O B P$ & $S L G$ \\
\hline A1 & 0.043 & 0.047 \\
\hline A2 & 0.039 & 0.036 \\
\hline A3 & 0.055 & 0.051 \\
\hline A4 & 0.054 & 0.062 \\
\hline A5 & 0.054 & 0.056 \\
\hline A6 & 0.040 & 0.037 \\
\hline A7 & 0.043 & 0.043 \\
\hline A8 & 0.049 & 0.051 \\
\hline A9 & 0.044 & 0.042 \\
\hline A10 & 0.040 & 0.039 \\
\hline A11 & 0.042 & 0.041 \\
\hline A12 & 0.046 & 0.041 \\
\hline A13 & 0.049 & 0.050 \\
\hline A14 & 0.048 & 0.053 \\
\hline A15 & 0.038 & 0.042 \\
\hline A16 & 0.041 & 0.037 \\
\hline A17 & 0.043 & 0.036 \\
\hline A18 & 0.054 & 0.064 \\
\hline A19 & 0.047 & 0.054 \\
\hline A20 & 0.046 & 0.041 \\
\hline A21 & 0.040 & 0.038 \\
\hline A22 & 0.045 & 0.038 \\
\hline
\end{tabular}

We reviewed previous studies [5-6] to determine the weights of OPB and SLG. The coefficient of OBP was approximately 2.6 times more than that of SLG [5-6]. Thus, we calculated the OBP and SLG coefficients as .722 and .278, respectively. We calculated the weighted normalized decision 
matrix by using Step 2. The weighted normalized decision matrix for each selection criterion is shown in Table III.

TABLE III. WEIGHTED NORMALIZED DECISION MATRIXES

\begin{tabular}{|c|c|c|}
\hline Player & OBP & $S L G$ \\
\hline A1 & 0.031 & 0.013 \\
\hline A2 & 0.028 & 0.010 \\
\hline A3 & 0.040 & 0.014 \\
\hline A4 & 0.039 & 0.017 \\
\hline A5 & 0.039 & 0.016 \\
\hline A6 & 0.029 & 0.010 \\
\hline A7 & 0.031 & 0.012 \\
\hline A8 & 0.035 & 0.014 \\
\hline A9 & 0.032 & 0.012 \\
\hline A10 & 0.029 & 0.011 \\
\hline A11 & 0.030 & 0.011 \\
\hline A12 & 0.033 & 0.011 \\
\hline A13 & 0.036 & 0.014 \\
\hline A14 & 0.035 & 0.015 \\
\hline A15 & 0.027 & 0.012 \\
\hline A16 & 0.029 & 0.010 \\
\hline A17 & 0.031 & 0.010 \\
\hline A18 & 0.039 & 0.018 \\
\hline A19 & 0.034 & 0.015 \\
\hline A20 & 0.033 & 0.011 \\
\hline A21 & 0.029 & 0.011 \\
\hline A22 & 0.033 & 0.011 \\
\hline PIS & 0.040 & 0.018 \\
\hline NIS & 0.027 & 0.010 \\
\hline
\end{tabular}

We calculated the positive $\left(S^{+}\right)$and negative $\left(S^{-}\right)$ideal solutions by using Steps 3 and 4, respectively; the values are shown in Table 3 . We calculated the distance of each alternative by using Step 5; the values are listed in Table 4 . We calculated the closeness coefficient $C C_{i}$ by using Step 6 . The all-river tracing route' $C C_{i}$ value and its rank are shown in Table IV.

TABLE IV. POSITIVE AND NEGATIVE IDEAL SOLUTIONS AND DISTANCE FOR EACH ALTERNATIVE, CLOSENESS COEFFICIENT AND RANK

\begin{tabular}{|c|c|c|c|c|}
\hline Player & $\boldsymbol{d}^{*}$ & $\boldsymbol{d}^{-}$ & $\boldsymbol{C C} \boldsymbol{~}$ & Rank \\
\hline A1 & $4.71 \mathrm{E}-05$ & $1.22 \mathrm{E}-05$ & 0.206 & 12 \\
\hline A2 & $9.54 \mathrm{E}-05$ & $4.46 \mathrm{E}-07$ & 0.005 & 22 \\
\hline A3 & $6.18 \mathrm{E}-06$ & $8.55 \mathrm{E}-05$ & 0.933 & 4 \\
\hline A4 & $2.14 \mathrm{E}-07$ & $9.79 \mathrm{E}-05$ & 0.998 & 1 \\
\hline A5 & $2.35 \mathrm{E}-06$ & $8.77 \mathrm{E}-05$ & 0.974 & 3 \\
\hline A6 & $8.24 \mathrm{E}-05$ & $1.84 \mathrm{E}-06$ & 0.022 & 18 \\
\hline A7 & $5.10 \mathrm{E}-05$ & $1.03 \mathrm{E}-05$ & 0.167 & 14 \\
\hline A8 & $1.60 \mathrm{E}-05$ & $4.08 \mathrm{E}-05$ & 0.719 & 6 \\
\hline A9 & $4.98 \mathrm{E}-05$ & $1.15 \mathrm{E}-05$ & 0.188 & 13 \\
\hline A10 & $8.17 \mathrm{E}-05$ & $1.70 \mathrm{E}-06$ & 0.020 & 19 \\
\hline A11 & $6.21 \mathrm{E}-05$ & $6.15 \mathrm{E}-06$ & 0.090 & 16 \\
\hline A12 & $4.13 \mathrm{E}-05$ & $1.85 \mathrm{E}-05$ & 0.310 & 10 \\
\hline A13 & $1.62 \mathrm{E}-05$ & $4.16 \mathrm{E}-05$ & 0.720 & 5 \\
\hline A14 & $1.65 \mathrm{E}-05$ & $3.91 \mathrm{E}-05$ & 0.703 & 7 \\
\hline A15 & $9.47 \mathrm{E}-05$ & $1.49 \mathrm{E}-06$ & 0.015 & 20 \\
\hline A16 & $8.02 \mathrm{E}-05$ & $2.23 \mathrm{E}-06$ & 0.027 & 17 \\
\hline A17 & $6.36 \mathrm{E}-05$ & $8.26 \mathrm{E}-06$ & 0.115 & 15 \\
\hline A18 & $2.86 \mathrm{E}-07$ & $9.75 \mathrm{E}-05$ & 0.997 & 2 \\
\hline A19 & $2.10 \mathrm{E}-05$ & $3.37 \mathrm{E}-05$ & 0.616 & 8 \\
\hline
\end{tabular}

\begin{tabular}{|c|c|c|c|c|}
\hline A20 & $4.05 \mathrm{E}-05$ & $1.92 \mathrm{E}-05$ & 0.321 & 9 \\
\hline A21 & $8.56 \mathrm{E}-05$ & $1.18 \mathrm{E}-06$ & 0.014 & 21 \\
\hline A22 & $4.87 \mathrm{E}-05$ & $1.57 \mathrm{E}-05$ & 0.244 & 11 \\
\hline
\end{tabular}

After employing the TOPSIS, we identified Player A4 as the best hitter in the 2013 season. This finding was expected because Player A4 ranked second in OBP and SLG. By contrast, Player A18 was the best performer in SLG, but ranked fourth in OBP; therefore, Player A18 ranked second among all candidates as the best hitter. Player A3 was the best performer in OBP; however, according to the TOPSIS, he ranked fourth among all candidates as the best hitter. Because of his performance in SLG, Player A3 ranked sixth among all players.

\section{CONCLUSION}

Evaluating the best hitter in a professional baseball league is difficult, and can be classified as a type of MADM problem. Most baseball fans or commentators judge the best hitter based on the number of home runs or hits scored by players. To evaluate the performance of the hitters in the 2013 CPBL season more objectively, we employed the TOPSIS to determine the best hitter in the Chinese professional baseball league. By using this method, we found that the best hitter was an outstanding performer in OBP and SLG. From a methodological perspective, the present study results demonstrated that the TOPSIS is an adequate tool for selecting the best alternative.

\section{ACKNOWLEDGMENT}

This research is partially supported by the Ministry of Science and Technology, Taiwan, R.O.C. under Grant no. MOST 104-2410-H-156-013.

\section{REFERENCES}

[1] C. C. Chen, M. L. Lin, Y. T. Lee, T. T. Chen and C. L. Huang, "Selection best starting pitcher of the Chinese professional baseball league in 2010 using AHP and TOPSIS methods," Advances in Intelligent and Soft Computing, 2002, vol. 133, pp.643-649.

[2] C. C. Chen, M. L. Lin, Y. T. Lee, T. T. Chen and C. Y. Tseng, Best Starting Pitcher of the Chinese Professional Baseball League in 2009, Proceeding of World Academy of Science, Engineering and Technology. 2010, vol. 72, pp. 210-212.

[3] C. C. Chen, Y. T. Lee and C. M. Tsai, Professional Baseball Team Starting Pitcher Selection using AHP and TOPSIS Methods, International Journal of Performance Analysis in Sport. 2014, vol.14, pp. 545-563.

[4] W. B. Lin, I. w. Tung, M. J. Chen and M. Y. Chen, An analysis of an optimal selection process for characteristics and technical performance of baseball pitchers, Perceptual and Motor Skills, 2011, vol. 133, pp. 300-310.

[5] J. K. Hakes and R. D. Sauer, An Economic Evaluation of the Moneyball Hypothesis, Journal of Economic Perspectives, 2006, vol. 20, pp. 173185.

[6] J. K. Hakes and R. D. Sauer, The Moneyball Anomaly and Payroll Efficiency: A Further Investigation, International Journal of Sport Finance, 2007, vol. 2, pp. 177-189.

[7] D. J. Berri and M. B. Schmidt, On the Evaluation of Kickers in the National Football League, International Journal of Sport Finance, 2013, vol.8, pp. 263-278.

[8] D. L. Olson, Comparison of Weights in TOPSIS Models, Mathematical and Computer Modelling, 2004, vol. 48, pp. 721-727. 